\title{
Effects of propofol on inflammatory response and activation of p38 MAPK signaling pathway in rats with ventilator-induced lung injury
}

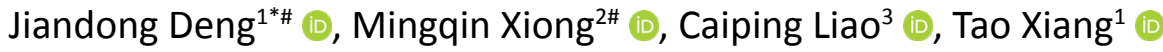 \\ 1. Bachelor. Department of Anesthesiology - The First Hospital of Changsha, China. \\ 2. Bachelor - Department of General Surgery - The First Hospital of Changsha, China. \\ 3. Master. Department of Anesthesiology - The First Hospital of Changsha, China.
}

\begin{abstract}
Purpose: To investigate the effects of propofol on inflammatory response and activation of p38 mitogen-activated protein kinase (MAPK) signaling pathway in rats with ventilator-associated lung injury (VALI). Methods: Thirty-six Sprague Dawley (SD) rats were divided into control, VALI and VALI+propofol groups. The VALI group received the mechanical ventilation for $2 \mathrm{~h}$. The VALI+propofol group received the mechanical ventilation for $2 \mathrm{~h}$, which was accompanied by intravenous injection of propofol with dose of $8 \mathrm{mg} \cdot \mathrm{kg}^{-1} \cdot \mathrm{h}^{-1}$. At the end, the mean arterial pressure (MAP) and blood gas indexes were measured, and the lung wet/dry mass ratio (W/D) and biochemical indexes of lung tissue and bronchoalveolar lavage fluid (BALF) were determined. Results: Compared with VALI group, in VALI+propofol group the blood $\mathrm{pH}$, partial pressure of oxygen, partial pressure of carbon dioxide and MAP were increased, the lung W/D, lung tissue myeloperoxidase activity and total protein concentration, white blood cell count, and tumor necrosis factor $\alpha$, interleukin $1 \beta$ and interleukin 6 levels in BALF were decreased, and the p-p38 MAPK protein expression level and phosphorylated p38 MAPK (p-p38 MAPK)/p38 MAPK ratio were decreased. Conclusion: Propofol treatment may alleviate the VALI in rats by reducing the inflammatory response and inhibiting the activation of p38 MAPK signaling pathway.
\end{abstract}

Key words: Propofol. Ventilators, Mechanical. Lung Injury. Inflammatory Response, Innate. p38 MAPK. Rats.

*Corresponding author: jiandongdenghn@126.com | +86-731-84910097

Received: June 26, 2021 | Review: Aug 22, 2021 | Accepted: Sept 24, 2021

Conflict of interest: Nothing to declare.

Research performed at Laboratory of The First Hospital of Changsha, China. 


\section{Introduction}

In recent years, the clinical application of ventilator is increasing, but the lung injury caused by improper use of ventilator or its long application time has gradually attracted the attention of clinicians ${ }^{1}$. If the ventilatorassociated lung injury (VALI) cannot be treated in time, it will seriously endanger the respiratory function of patients, and even lead to death. At present, it is believed that the variation of proinflammatory mediators, changes in cell conformation, remodeling of cytoskeleton, activation of signal transduction pathway and apoptosis of pulmonary epithelial cells play important roles in VALI ${ }^{2-4}$.

In clinic, VALI is mainly treated by carbon dioxide inhalation, anti-inflammatory treatment, adrenoceptor drug therapy and renin-angiotensin-aldosterone system drug therapy, but there is no drug to specifically improve the prognosis of VALI. Propofol is an alkyl acid shortacting intravenous sedative which is currently used for the induction and maintenance of anesthesia, especially for minor surgery, outpatient biopsy and sedation of patients in critical care unit ${ }^{5,6}$. It is found that propofol can alleviate the vomiting, immune response, anxiety, and pain, besides protecting the nervous system ${ }^{7}$. Propofol is also a commonly used drug for sedation during mechanical ventilation. It has anti-inflammatory properties, can reduce the lung injury and improve the oxygenation during mechanical ventilation, but the mechanism is unclear ${ }^{8,9}$.

It is found that the p38 mitogen-activated protein kinase (MAPK) signaling pathway is closely related to the lung injury ${ }^{10-12}$. This study was designed to investigate the effects of propofol on inflammatory response and activation of p38 MAPK signaling pathway in rats with VALI.

\section{Methods}

This study was approved by the ethics committee of the First Hospital of Changsha. All animal procedures were in accordance with the Guide for the Care and Use of Laboratory Animals by the National Institutes of Health.

\section{Animals and grouping}

Thirty-six specific-pathogen-free (SPF)-grade male Sprague Dawley rats (250-300 g; Shanghai Slake Experimental Animal Co.) were maintained under condition of $12-\mathrm{h} / 12-\mathrm{h}$ light/dark cycle, temperature of $22 \pm 2^{\circ} \mathrm{C}$ and humidity of $50 \pm 5 \%$. After one week of adaptive feeding, the rats were randomly divided into control, VALI and VALI+propofol groups (12 animals in each group).

\section{Establishment of VALI model and treatment}

In VALI and VALI+propofol groups, the rats were anesthetized with $13.3 \%$ urethane combined with $0.5 \%$ chloraldose, followed by fixing. The trachea was cut open. A 16-gauge venous indwelling catheter was inserted into the trachea and connected to a small animal ventilator for mechanical ventilation. The tidal volume was set as $30 \mathrm{~mL} / \mathrm{kg}$, and the ventilation time was $2 \mathrm{~h}$. In addition, in VALI+propofol group, during the mechanical ventilation, propofol was intravenously injected, with dose of $8 \mathrm{mg} \cdot \mathrm{kg}^{-1} \cdot \mathrm{h}^{-1}$. In control group, the rats received the spontaneous breathing, without mechanical ventilation.

\section{Mean arterial pressure monitoring and blood gas analysis}

At the end of mechanical ventilation, the mean arterial pressure (MAP) of rats was monitored. In addition, $0.3 \mathrm{~mL}$ of arterial blood was collected for blood gas analysis. The blood $\mathrm{pH}$, partial pressure of oxygen $\left(\mathrm{PaO}_{2}\right)$, and partial pressure of carbon dioxide $\left(\mathrm{PaCO}_{2}\right)$ were measured.

\section{Determination of lung wet/dry mass ratio}

The rats were sacrificed. The right middle lung tissue was taken. The blood and water on the surface were sucked dry with absorbent paper. The lung tissue was weighed to obtain the wet mass (mg). Then, the lung tissue was dried in $80^{\circ} \mathrm{C}$ drying oven to constant weight to obtain the dry mass $(\mathrm{mg})$. The lung wet/dry mass ratio (W/D) was obtained.

\section{Determination of biochemical indexes of bronchoalveolar lavage fluid}

The lavage of left lung was performed using normal saline. The bronchoalveolar lavage fluid (BALF) was obtained, followed by centrifuging at 1,000 r/min for $10 \mathrm{~min}$. The precipitate was diluted with phosphate buffered saline. After Wright's staining, the white blood cells were counted under light microscope. The total protein concentration in BALF was determined by Coomassie brilliant blue staining. The tumor necrosis factor $\alpha$ (TNF- $\alpha$ ), interleukin $1 \beta$ (IL-1 $\beta$ ) and interleukin 6 (IL-6) were detected by double-antibody sandwich indirect enzyme-linked immunosorbent assay. All operations were carried out in strict accordance with the requirements of the kit instructions.

\section{Determination of biochemical indexes of lung tissue}

The left lung tissue was taken and homogenized. The protein was extracted using radio-immunoprecipitation assay (RIPA) buffer, and the protein concentration 
was determined by Coomassie brilliant blue method. The myeloperoxidase activity in lung tissue was measured using the specific kit. The expressions levels of p38 MAPK and phosphorylated p38 MAPK ( $p$-p38 MAPK) proteins were determined using western blot assays. The procedures were in accordance with the instructions of kits.

\section{Statistical analysis}

Data were presented as mean \pm standard deviation and analyzed using Statistical Package for the Social Sciences (SPSS) 18.0 software. The comparisons among three groups were performed using single-factor analysis of variance test with post-hoc Student-Newman-Keuls (SNK) test. $\mathrm{P}<0.05$ and $\mathrm{P}<0.01$ were considered significant and highly significant, respectively.

\section{Results}

\section{Comparison of blood $\mathrm{pH}, \mathrm{PaO}_{2}, \mathrm{PaCO}_{2}$ and MAP among three groups}

At the end of mechanical ventilation, the blood $\mathrm{pH}$, $\mathrm{PaO}_{2}, \mathrm{PaCO}_{2}$ and MAP had significant difference in three groups, respectively $(P<0.001)$. Compared with control group, each index in VALI and VALI+propofol groups was significantly decreased, respectively $(P<0.01)$. Compared with VALI group, each index in VALI+propofol group was significantly increased $(P<0.01)$ (Table 1$)$.

\section{Comparison of lung W/D and lung tissue myeloperoxidase activity among three groups}

As shown in Table 2, at the end of mechanical ventilation, the lung W/D and lung tissue myeloperoxidase activity had significant difference in three groups $(P<0.001)$. Each index in VALI and VALI+propofol groups was significantly higher than that in control group $(P<0.01)$, and each index in VALI+propofol group was significantly lower than that in VALI group $(P<0.01)$.
Table 2 - Comparison of lung W/D and lung tissue myeloperoxidase activity among three groups.

\begin{tabular}{ccc}
\hline Group & Lung W/D & Myeloperoxidase $(\mathbf{U} / \mathbf{g})$ \\
\hline Control & $3.54 \pm 0.56$ & $0.85 \pm 0.12$ \\
VALI & $5.18 \pm 0.78^{\mathrm{a}}$ & $2.38 \pm 0.37^{\mathrm{a}}$ \\
VALI+propofol & $4.37 \pm 0.39^{\mathrm{ab}}$ & $1.43 \pm 0.19^{\mathrm{ab}}$ \\
F & 22.538 & 114.615 \\
$\mathrm{P}$ & $<0.001$ & $<0.001$ \\
\hline
\end{tabular}

${ }^{\mathrm{a}} \mathrm{P}<0.01$ vs. control group; ${ }^{\mathrm{b}} \mathrm{P}<0.01$ vs. VALI group; VALI: ventilator-associated lung injury; W/D: wet/dry mass ratio; $F$ : statistics of single-factor analysis of variance test.

\section{Comparison of total protein concentration and white blood cell count in BALF among three groups}

At the end of mechanical ventilation, there was significant difference of total protein concentration and white blood cell count in BALF among three groups $(P<0.001)$. Compared with control group, each index in VALI and VALI+propofol groups was significantly increased $(P<0.01)$. Compared with VALI group, each index in VALI+propofol group was significantly decreased $(P<0.01)$ (Table 3).

Table 3 - Comparison of total protein concentration and white blood cell count in BALF among three groups.

\begin{tabular}{ccc} 
Group & $\begin{array}{c}\text { Total protein } \\
\text { concentration }(\mathbf{g} / \mathbf{L})\end{array}$ & $\begin{array}{c}\text { White blood cell } \\
\text { count }\left(\mathbf{1 \times 1 0 ^ { 7 }} / \mathbf{L}\right)\end{array}$ \\
\hline Control & $0.41 \pm 0.06$ & $39.92 \pm 5.06$ \\
VALI & $1.48 \pm 0.18^{\mathrm{a}}$ & $121.38 \pm 19.37^{\mathrm{a}}$ \\
VALI+propofol & $0.72 \pm 0.12^{\mathrm{ab}}$ & $65.05 \pm 9.28^{\mathrm{ab}}$ \\
F & 216.500 & 128.650 \\
$\mathrm{P}$ & $<0.001$ & $<0.001$ \\
\hline
\end{tabular}

${ }^{\text {aP }}<0.01$ vs. control group; ${ }^{\text {b }}<<0.01$ vs. VALI group; VALI: ventilator-associated lung injury; F: statistics of single-factor analysis of variance test.

Table 1 - Comparison of blood $\mathrm{pH}, \mathrm{PaO}_{2}, \mathrm{PaCO}_{2}$ and MAP among three groups.

\begin{tabular}{ccccc}
\hline Group & $\mathbf{p H}$ & $\mathbf{P a O}_{\mathbf{2}}(\mathbf{m m H g})$ & $\mathbf{P a C O}_{\mathbf{2}}(\mathbf{m m H g})$ & $\mathbf{M A P}(\mathbf{m m H g})$ \\
\hline Control & $7.40 \pm 0.04$ & $99.30 \pm 14.72$ & $40.17 \pm 6.35$ & $123.06 \pm 5.40$ \\
VALI & $7.16 \pm 0.05^{\mathrm{a}}$ & $65.06 \pm 10.20^{\mathrm{a}}$ & $69.54 \pm 8.19^{\mathrm{a}}$ & $89.12 \pm 6.19^{\mathrm{a}}$ \\
VALI+propofol & $7.30 \pm 0.04^{\mathrm{ab}}$ & $78.28 \pm 7.06^{\mathrm{ab}}$ & $56.68 \pm 7.04^{\mathrm{ab}}$ & $103.32 \pm 7.04^{\mathrm{ab}}$ \\
F & 91.789 & 28.967 & 49.715 & 89.368 \\
P & $<0.001$ & $<0.001$ & $<0.001$ & $<0.001$ \\
\hline
\end{tabular}

${ }^{\mathrm{a}} \mathrm{P}<0.01$ vs. control group; ${ }^{\mathrm{b}} \mathrm{P}<0.01$ vs. VALI group; VALI: ventilator-associated lung injury; $\mathrm{PaO}_{2}$ : partial pressure of oxygen; $\mathrm{PaCO}{ }_{2}$, partial pressure of carbon dioxide; MAP, mean arterial pressure. 
Comparison of TNF- $\alpha, I L-1 \beta$ and IL-6 levels in BALF among three groups

Table 4 shows that, at the end of mechanical ventilation, TNF- $\alpha$, IL-1 $\beta$ and IL-6 levels in BALF had significant difference in three groups $(\mathrm{P}<0.001)$. Each index in VALI and VALI+propofol groups was significantly higher than that in control group $(P<0.01)$, and each index in VALI+propofol group was significantly lower than that in VALI group $(P<0.01)$.

Table 4 - Comparison of TNF- $\alpha$, IL-1 $\beta$ and IL- 6 levels in BALF among three groups.

\begin{tabular}{cccc}
\hline Group & $\begin{array}{c}\text { TNF- } \alpha \\
(\mathbf{p g} / \mathbf{m L})\end{array}$ & $\begin{array}{c}\text { IL-1 } \beta \\
(\mathbf{p g} / \mathbf{m L})\end{array}$ & IL-6 $(\mathbf{p g} / \mathbf{m L})$ \\
\hline Control & $67.38 \pm 9.42$ & $45.83 \pm 6.04$ & $39.05 \pm 7.24$ \\
VALI & $281.20 \pm 36.28^{\mathrm{a}}$ & $201.47 \pm 38.21^{\mathrm{a}}$ & $121.25 \pm 19.82^{\mathrm{a}}$ \\
VALI+propofol & $124.16 \pm 23.19^{\mathrm{ab}}$ & $89.84 \pm 15.33^{\mathrm{ab}}$ & $61.72 \pm 11.77^{\mathrm{ab}}$ \\
F & 227.321 & 133.833 & 111.150 \\
$\mathrm{P}$ & $<0.001$ & $<0.001$ & $<0.001$
\end{tabular}

aP $<0.01$ vs. control group; ${ }^{b} \mathrm{P}<0.01$ vs. VALI group; VALI: ventilator-associated lung injury; TNF- $\alpha$ : tumor necrosis factor

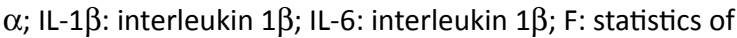
single-factor analysis of variance test.

\section{Comparison of p38 MAPK and p-p38 MAPK protein} expression levels in lung tissue among three groups

At the end of mechanical ventilation, there was no significant difference of p38 MAPK protein expression level in lung tissue among three groups $(P>0.05)$, with significant difference of $\mathrm{p}-\mathrm{p} 38$ MAPK protein expression level among three groups $(P<0.001)$. Compared with control group, p-p38 MAPK protein expression level and p-p38 MAPK/p38 MAPK ratio in VALI and VALI+propofol groups were significantly increased $(P<0.01)$. Compared with VALI group, each index in VALI+propofol group was significantly decreased $(P<0.01)$ (Table 5$)$.

Table 5 - Comparison of p38 MAPK and p-p38 MAPK protein expression levels in lung tissue among three groups.

\begin{tabular}{cccc}
\hline Group & $\begin{array}{c}\text { p38 MAPK/ } \beta- \\
\text { actin }\end{array}$ & $\begin{array}{c}\text { p-p38 MAPK/ } \\
\beta \text {-actin }\end{array}$ & $\begin{array}{c}\text { p-p38 MAPK/ } \\
\text { p38 MAPK }\end{array}$ \\
\hline Control & $1.06 \pm 0.15$ & $0.79 \pm 0.12$ & $0.77 \pm 0.18$ \\
VALI & $1.09 \pm 0.13$ & $1.78 \pm 0.26^{\mathrm{a}}$ & $1.66 \pm 0.27^{\mathrm{a}}$ \\
VALI+propofol & $1.15 \pm 0.17$ & $1.27 \pm 0.16^{\mathrm{ab}}$ & $1.11 \pm 0.04^{\mathrm{ab}}$ \\
F & 1.107 & 116.958 & 67.925 \\
P & 0.343 & $<0.001$ & $<0.001$ \\
\hline
\end{tabular}

ap $<0.01$ vs. control group; ${ }^{\text {b }}<0.01$ vs. VALI group; VALI: ventilator-associated lung injury; MAPK: mitogen-activated protein kinase; $\mathrm{F}$ : statistics of single-factor analysis of variance test.

\section{- Discussion}

In the emergency treatment or rescue of critically ill patients, the use of ventilator is the most common and effective for mechanical ventilation. Despite the protective ventilation strategy, VALI is still one of the high risk factors ${ }^{13,14}$. Therefore, it is an inevitable trend to explore measures to prevent VALI.

In this study, the protective effects of propofol on rats with VILI were investigated. Results showed that, after $2 \mathrm{~h}$ of mechanical ventilation, compared with control group, the blood $\mathrm{pH}, \mathrm{PaO}_{2}, \mathrm{PaCO}_{2}$ and MAP in VALI and VALI+propofol groups were significantly decreased. Compared with VALI group, each index in VALI+propofol group was significantly increased. This indicates that the propofol treatment can improve the pulmonary function of rats during mechanical ventilation.

Lung W/D reflects the degree of pulmonary edema, and the total protein concentration in BALF reflects the pulmonary exudation. The lung tissue myeloperoxidase activity and white blood cell count reflect the white blood cell infiltration of lung tissue. In this study, at the end of mechanical ventilation, compared with control group, the lung $W / D$, lung tissue myeloperoxidase activity and total protein concentration and white blood cell count in BALF in VALI and VALI+propofol groups were significantly increased. Compared with VALI group, each index in VALI+propofol group was significantly decreased. It suggests that the VALI occurs in rats, and the propofol treatment can alleviate the VALI.

There are many abnormal changes of the immune system in VALI, which is closely related to the release of inflammatory factors and inflammatory response. At the same time, the inflammatory response will aggravate the VALI ${ }^{15}$. Previous study ${ }^{16}$ has found that there is abnormal inflammatory response in rat VALI model. After treatment by curcumin with anti-inflammatory properties, the VALI is alleviated, and the release of inflammatory factors and activation of neutrophils are decreased.

Another study ${ }^{17}$ has shown that pycnogenol extracted from pine bark can resist the VALI, and reduce the lung tissue TNF- $\alpha$, IL-1 $\beta$ and IL- 6 levels. In our study, at the end of mechanical ventilation, the TNF- $\alpha$, IL- $1 \beta$ and IL- 6 levels in BALF in VALI and VALI+propofol groups were significantly higher than those in control group, and each index in VALI+propofol group was significantly lower than that in VALI group. It confirms that the propofol treatment can decrease the inflammatory response, which is related to its alleviative effect on VALI in rats.

Studies have shown that the initiation of pulmonary inflammatory response is closely related to the activation of inflammatory signal transduction pathway. The p38 MAPK 
pathway plays a particularly important role in lung injury. This pathway is coupled with the mechanical stimulation sensor and is also related to the transcription and expression of a variety of inflammatory substances ${ }^{18,19}$. After p38 MAPK pathway is activated, the inactive threonine and tyrosine are phosphorylated to form p-p38 MAPK protein. p-p38 MAPK protein can up-regulate the expression of a variety of inflammatory factors ${ }^{20}$.

Results of this study showed that, at the end of mechanical ventilation, there was no significant difference of 38 MAPK protein expression level in lung tissue among the three groups. However, compared with control group, the $p$-p38 MAPK protein expression level and p-p38 MAPK/ p38 MAPK ratio in VALI and VALI+propofol groups were significantly increased. Compared with VALI group, each index in VALI+propofol group was significantly decreased. It indicates that the p38 MAPK signaling pathway is activated in mechanical ventilation, and the propofol treatment can inhibit the activation of p38 MAPK signaling pathway, thus reducing the VALI.

\section{Conclusions}

The propofol treatment can alleviate the VALI in rats. The mechanism may be associated with reducing the inflammatory response and inhibiting the activation of p38 MAPK signaling pathway. This study has provided a new theoretical basis for the application of propofol in VALI and a new clue for the prevention and treatment of VALI.

This study, however, has some limitations. Firstly, the sample size of animals is relatively small, which may affect the persuasiveness of the results. Secondly, there may be other mechanisms related to the protective effect of propofol on VALI, which have not been investigated here. These issues need to be solved in the follow-up research.

\section{Authors' contribution}

Design of the study: Deng J; Acquisition of data: Liao C; Technical procedures: Xiong M; Statistical analysis: Liao C; Manuscript preparation: Xiang T; Critical revision: Deng $\mathrm{J}$; Final approval of the version to be published: Deng J, Xiong $\mathrm{M}$, Liao $\mathrm{C}$ and Xiang T. \#The authors contributed equally to this work.

\section{Data availability statement}

Data will be available upon request.

\section{Funding}

Not applicable.

\section{Acknowledgments}

Not applicable.

\section{References}

1. Tsumura H, Harris E, Brandon D, Pan W, Vacchiano C. Review of the mechanisms of ventilator induced lung injury and the principles of intraoperative lung protective ventilation. AANA J. 2021;89:227-33.

2. Monjezi $M$, Jamaati $H$, Noorbakhsh F. Attenuation of ventilator-induced lung injury through suppressing the proinflammatory signaling pathways: a review on preclinical studies. Mol Immunol. 2021;135:127-36. https://doi. org/10.1016/j.molimm.2021.04.007

3. Kim SH, Li M, Pyeon TH, So KY, Kwak SH. The volatile anesthetic sevoflurane attenuates ventilator-induced lung injury through inhibition of ERK1/2 and Akt signal transduction. Korean J Anesthesiol. 2015;68:62-9. https:// doi.org/10.4097/kjae.2015.68.1.62

4. Zhu H, He J, Liu J, Zhang X, Yang F, Liu P, Wang S. Alpha 1-antitrypsin ameliorates ventilator-induced lung injury in rats by inhibiting inflammatory responses and apoptosis. Exp Biol Med (Maywood). 2018;243:87-95. https://doi. org/10.1177/1535370217740852

5. Chidambaran V, Costandi A, D'Mello A. Propofol: a review of its role in pediatric anesthesia and sedation. CNS Drugs. 2015;29:543-63. https://doi.org/10.1007/s40263-0150259-6

6. Wang H, Zhang S, Zhang A, Yan C. Propofol prevents the progression of malignant pheochromocytoma in vitro and in vivo. DNA Cell Biol. 2018;37:308-15. https://doi. org/10.1089/dna.2017.3972.

7. Dinis-Oliveira RJ. Metabolic profiles of propofol and fospropofol: clinical and forensic interpretative aspects. Biomed Res Int. 2018;2018:6852857. https://doi. org/10.1155/2018/6852857

8. Li SP, Zhou XL, Zhao Y. Sedation with midazolam worsens the diaphragm function than dexmedetomidine and propofol during mechanical ventilation in rats. Biomed Pharmacother. 2020;121:109405. https://doi. org/10.1016/j.biopha.2019.109405

9. Elgebaly AS, Sabry M. Sedation effects by dexmedetomidine versus propofol in decreasing duration of mechanical ventilation after open heart surgery. Ann Card Anaesth. 2018;21:235-42. https://doi.org/10.4103/aca. ACA_168_17

10. Nakata K, Okazaki M, Shimizu D, Suzawa K, Shien K, Miyoshi $K$, Otani S, Yamamoto H, Sugimoto S, Yamane M, Ousaka D, Ohara T, Matsukawa A, Nishibori M, Toyooka S. Protective effects of anti-HMGB1 monoclonal antibody on lung ischemia reperfusion injury in mice. Biochem Biophys Res Commun. 2021;573:164-70. https://doi.org/10.1016/j. bbrc.2021.08.015 
11. Ali FEM, Ahmed SF, Eltrawy AH, Yousef RS, Ali HS, Mahmoud AR, Abd-Elhamid TH. Pretreatment with coenzyme Q10 combined with aescin protects against sepsis-induced acute lung injury. Cells Tissues Organs. 2021:1-23. https:// doi.org/10.1159/000516192

12. Hu XH, Situ HL, Chen JP, Yu RH. Lipoxin A4 alleviates lung injury in sepsis rats through p38/MAPK signaling pathway. J Biol Regul Homeost Agents. 2020;34:807-14. https://doi. org/10.23812/20-108-A-20

13. Beitler JR, Malhotra A, Thompson BT. Ventilator-induced Lung Injury. Clin Chest Med. 2016;37:633-46. https://doi. org/10.1016/j.ccm.2016.07.004

14. Gattinoni L, Giosa L, Bonifazi M, Pasticci I, Busana M, Macri $\mathrm{M}$, Romitti F, Vassalli F, Quintel M. Targeting transpulmonary pressure to prevent ventilator-induced lung injury. Expert Rev Respir Med. 2019;13:737-46. https://doi.org/10.1080 /17476348.2019.1638767

15. Borges JB, Costa EL, Suarez-Sipmann F, Widström C, Larsson A, Amato M, Hedenstierna G. Early inflammation mainly affects normally and poorly aerated lung in experimental ventilator-induced lung injury. Crit Care Med. 2014;42:e279-87. https://doi.org/10.1097/ CCM.0000000000000161
16. Wang X, An X, Wang X, Bao C, Li J, Yang D, Bai C. Curcumin ameliorated ventilator-induced lung injury in rats. Biomed Pharmacother. 2018;98:754-61. https://doi.org/10.1016/j. biopha.2017.12.100

17. Xia YF, Zhang JH, Xu ZF, Deng XM. Pycnogenol, a compound isolated from the bark of pinus maritime mill, attenuates ventilator-induced lung injury through inhibiting NF-KBmediated inflammatory response. Int J Clin Exp Med. 2015;8:1824-33.

18. Chen J, Xue X, Cai J, Jia L, Sun B, Zhao W. Protective effect of taurine on sepsis-induced lung injury via inhibiting the p38/MAPK signaling pathway. Mol Med Rep. 2021;24:653. https://doi.org/10.3892/mmr.2021.12292

19. Huang J, Liu J, Chang G, Wang $Y$, Ma N, Roy AC, Shen $X$. Glutamine supplementation attenuates the inflammation caused by LPS-induced acute lung injury in mice by regulating the TLR4/MAPK signaling pathway. Inflammation. 2021. Epub ahead of print. https://doi. org/10.1007/s10753-021-01491-2

20. Wei S, Huang Q, Li J, Liu Z, You H, Chen Y, Gong J. Taurine attenuates liver injury by downregulating phosphorylated p38 MAPK of Kupffer cells in rats with severe acute pancreatitis. Inflammation. 2012;35:690-701. https://doi. org/10.1007/s10753-011-9362-0 